\title{
Influence Model Research of Brand Culture on Home Textile Consumption Behavior
}

\author{
Lingling Ju${ }^{1}$, Dong Yan $^{1}$, Xiaoyan Wang ${ }^{1} \&$ Shouzhong $\mathrm{Hu}^{1}$ \\ ${ }^{1}$ School of Fashion, Shanghai University of Engineering Science, Shanghai, China \\ Correspondence: Shouzhong Hu, School of Fashion, Shanghai University of Engineering Science, Shanghai, China. \\ E-mail: hushzh@sues.edu.cn
}

Received: April 5, 2016

Accepted: April 10, 2016

Online Published: April 16, 2016

doi:10.5430/jbar.v5n1p34

URL: http://dx.doi.org/10.5430/jbar.v5n1p34

\begin{abstract}
Through the analysis of the influence for brand culture on home textile consumption behavior, extracted the influence factors of brand culture on consumer behavior in home textile consumption behavior, put forward one theory model which 4 dimensions of brand culture as the independent variable, home textile consumers' purchase attitude as an intermediate variable, home textile consumer brand choice of purchase behavior as the dependent variable, and to further establish a reasonable influence relationship model between the brand culture on home textile consumer behavior. By using SPSS, AMOS analysis software, etc, through expert interview and questionnaire investigation, comprehensive reliability analysis, factor analysis, SEM and other methods for selecting the factors and model building, to promote enterprises to form the unique brand culture characteristics.
\end{abstract}

Keywords: Brand culture, Home textile, Consumption behavior, Structural equation

\section{Introduction}

Asia Pacific home network data show: home textiles, clothing textiles, industrial textiles for the three major textiles, domestic home textile consumption in China only accounts for $20 \%$ of the total amount of textiles, but in the developed countries, particularly in the United States and Japan, up to $40 \%$ of household textiles, Britain, France and other countries of the consumption is stable at $35 \%-38 \%$, has become the first big consumption more than clothing. Consumers are in the society, abstract culture is a profound impact on the specific purchase behavior.

In this paper, the influence of brand culture on consumer behavior in the field of home textile consumption is analyzed, exactly research the influence of attitudes and behavior on brand culture on consumer to buy what kind of home textiles, why buy, when to buy, where to buy, will buy again. What is based on brand's external behavior, home textile products based on the functionality of artistic expression, the brand culture of advertising and marketing communication behavior, brand culture core spirit which four components of elements of brand culture.

Consumer behavior research mainly focuses on the research of influencing factors model, the theoretical study of the western consumer behavior influence factors is more mature, domestic research is more applied research. Western consumer behavior influence factor model is as follows: (1) Del Hawkins model. "Know questions, gather information, evaluate and choose, shop choose and buy, activities after buy". (2) Roger Blackwell model. Consumer factors + Organizational factors. (3) Frank Kardes model. Emotional, cognitive, and behavioral reaction process. (4) John Mowen model. Exchange process, emphasize the theory of experience and environmental impact. (5) Mark.E.Parry model. The realization process of consumer's personal value. Two trends in consumer behavior research worthy of attention is (Huang Ming \& Xue Yunjian, 2015): attach great importance to establish the exchange relationship, maintain and develop the consumer behavior research; pay attention to consumer, marketing effect and experience of consumer behavior research.

\section{Research Variable Design of Influence Factors and Research Hypothesis of Influence Relationship}

\subsection{Research Variable Design}

Through the literature review on brand culture, consumer behavior and the features of home textile product, then a basic understanding of both the effect of logical structure. This chapter will combine the features of home textile products, with the model of brand composition, the role model of brand culture on consumer psychology, Mowen John model (emphasis on experiential theory and marketing theory) as the basis, to determine the research variables 
of this paper (this study is referred to as potential variables) and the evaluation index system of each variable (the study is called the observation variable).

\subsubsection{Determination of Potential Variables}

Potential variables of brand culture in accordance with the theory of three levels, respectively, the brand culture material presentation, brand culture spread behavior layer, brand culture spirit layer, the attributes of home textile products set separately as latent variables too, brand culture has set a total of four latent variables. Two latent variables in terms of consumer, the consumer attitudes as intermediate variables, and the consumers purchasing behavior was eventually affected as the last potential variables.

\subsubsection{Determination of Observation Variables}

Latent variables set based on the consideration of brand culture elements and home textile consumer behavior, using the methods of experts, consumer research, literature review, research and collation of observation indicators are as follows:

First class indicator: A brand culture of the external manifestation of the brand, B product based on the function of the artistic expression, $\mathrm{C}$ the spread and promotion of brand culture, D the core connotation of brand culture, $\mathrm{E}$ consumer buying attitudes, $\mathrm{F}$ consumer purchase behavior.

Second class indicator: A1 based on brand culture external expression; B1 based on product practical function, B2 higher aesthetic expression; $\mathrm{C} 1$ based on the route of transmission of communication, $\mathrm{C} 2$ based on the spread of advertising, C3 based on the spread of social relations; D1 brand culture values, D2 formation of brand culture; E1 consumer emotion, E2 consumer cognition; F1 consumers get behavior, F2 consumers using disposal behavior.

Third class indicator (30): A11 brand name, A12 brand logo, A13 brand slogan, A14 smell, A15 brand packaging; B11 product modelling style design, B12 product material research and development, B13 product aromatic physiotherapy research and development, B21 product pattern design, B22 product color design, B23 product style design; C11 online shop, C12 shop theme pavilion, C21 traditional media advertising, C22 store display environment, C23 new media platform for advertising, C24 advertising spokesperson, C31 public relations activities, C32 word of mouth; D11 brand idea, D12 brand reputation, D13 brand personality, D21 national culture, D22 brand history; E11 product matching, E12 indoor environment, E21 public recognition; F11 shop scene, F12 reasonable price, F21 regular re purchase.

\subsubsection{Evaluation Index Selection}

This research adopts 5 point Likert scale measurement scale, and fine screening on three indicators to better measure first class indicators. Output by SPSS20.0 statistical analysis, some can merge together to discuss consistent identify new 20 third class indicators as the following: A11 brand logo, A12 brand packaging; B11 style and material, B21 pattern and color, B22 integration of technology and art; C11 online shop, C21 traditional media communication, C22 spread of new media platforms, C23 spokesperson and public relations; D11 brand idea, D12 brand reputation, D13 brand personality, D21 national culture, D22 brand history; E11 product matching, E12 indoor environment, E21 public recognition; F11 shop scene, F12 reasonable price, F21 regular re purchase.

\subsection{Research Hypothesis of the Influence Relationship}

The influencing relation of brand culture material on consumer behavior

Research hypothesis one (H1): The external performance of the brand culture has a significant positive correlation with the purchase attitude of consumers.

Research hypothesis two (H2): Products based on the functionality of artistic expression has a significant positive correlation with the purchase attitude of consumers.

The influencing relation of brand cultural behavior factors on consumer behavior

Research hypothesis three (H3): Dissemination and promotion of brand culture has a significant positive correlation with the purchase attitude of consumers.

Research hypothesis four (H4): Dissemination and promotion of brand culture has a significant positive correlation with the purchase behavior of consumers.

The influencing relation of brand cultural spirit factors on consumer behavior

Research hypothesis five (H5): Core connotation of brand culture has a significant positive correlation with the purchase attitude of consumers. 
Research hypothesis six (H6): Core connotation of brand culture has a significant positive correlation with the purchase behavior of consumers.

The influencing relation of consumer attitude on consumer behavior

Research hypothesis seven (H7): Purchase attitude of brand culture has a significant positive correlation with the purchase behavior of consumers.

\section{Concept Model Building of Influencing Factors}

On the basis of the indicators variables identified and assumptions relationship, this paper establishes a conceptual model based on consumer perceived brand culture as shown in Figure 1:

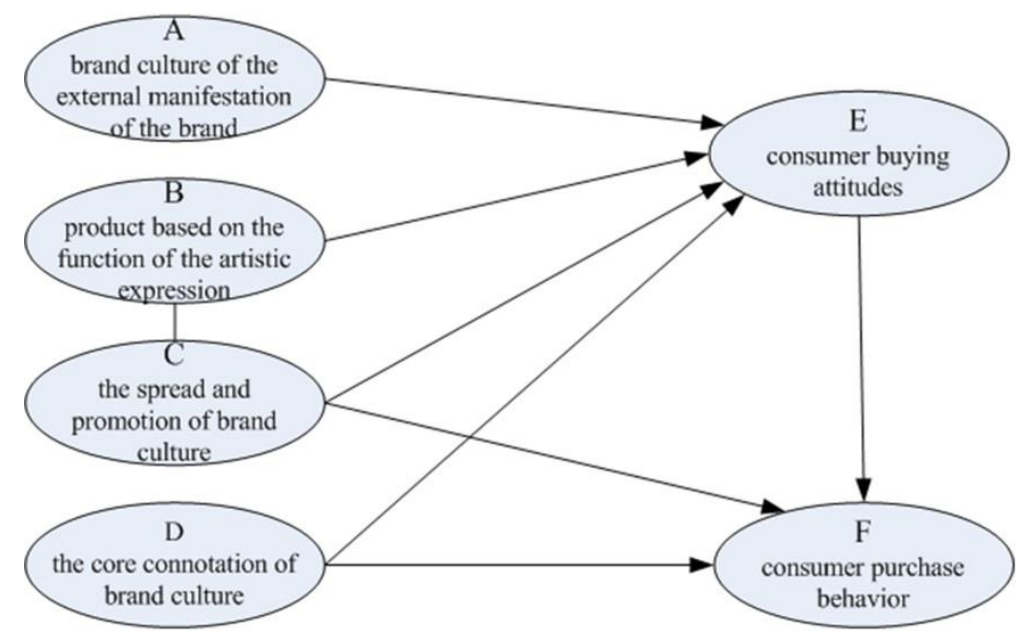

Figure 1. conceptual model diagram

\section{Influence Model Analysis}

In this paper, we designed and distributed 500 questionnaires, 371 valid samples, the recovery rate was $77 \%$, and the effective rate was $74.2 \%$. According to the analysis of the descriptive analysis, reliability analysis, factor analysis and structural equation, to establish a reasonable relationship model for brand culture influence on home textile consumer behavior.

\subsection{Reliability Test}

Reliability statistics is: the Cronbach's Alpha 0.795, number 20. 0.795 belong to the range of $0.7 \sim 0.8$, good reliability.

From SPSS reliability analysis totaled statistics table display: item "C11 online shop" corrected item total correlation is 0.372 , CITC (correction term total correlation) coefficient is less than 0.4 and delete the item scale Cronbach's alpha value will increase, and the scale of homogeneity is not high, be deleted.

\subsection{Validity Test}

Using KMO statistic and Bartlett spherical test to evaluate the index of brand culture scale, and to see whether it is suitable for factor analysis. Analysis: sampling enough Kaiser-Meyer-Olkin metric is 0.739; sphericity test of Bartlett approximation chi square 932.667 , df 78, Sig. 0.000. According to Kaiser (1974) point of view, if the KMO value is less than 0.5 that is not suitable for factor analysis; if between 0.7-0.8, suitable for factor analysis; between 0.8-0.9, very suitable; more than 0.9 , fit well.

The results show that the KMO value is 0.739 , which is between $0.7-0.8$, and is suitable for factor analysis. The rotational component matrix is shown in Table 1: 
Table 1. Rotational component matrix of the brand culture factor scale

\begin{tabular}{lcccc}
\hline & & & Component & \\
& 1 & 2 & 3 & 4 \\
\hline D13 Brand personality & .680 & -.014 & .165 & .235 \\
D21 National culture & .664 & -.055 & .163 & -.034 \\
D11 Brand idea & .656 & .125 & -.163 & .144 \\
D22 brand history & .655 & .117 & .053 & .053 \\
D12 Brand reputation & .632 & .010 & -.113 & .246 \\
B21 Pattern and color & -.034 & .848 & .130 & -.013 \\
B11 Style and material & .017 & .801 & .086 & .014 \\
B22 Integration of technology and art & .158 & .710 & .127 & .051 \\
C22 Spread of new media platforms & .062 & .070 & .801 & .018 \\
C21 Traditional media communication & -.105 & .098 & .746 & .143 \\
C23 Spokesperson and public relations & .125 & .181 & .678 & -.015 \\
A11 Brand logo & .186 & .027 & .126 & .831 \\
A12 Brand packaging & .215 & .022 & .015 & .821 \\
Extraction method: principal component. & & & & \\
Rotation method: an orthogonal rotation method with Kaiser standardization. & & \\
a. Rotation after 5 iterations of convergence. & & & &
\end{tabular}

From the Table 1 can be drawn, after factor analysis, the cumulative variance percentage is higher than 50\%, the statistical analysis results show that the scale of the construct validity is very good.

The KMO and Bartlett tests on consumer buying attitudes and behavior scales show that the Kaiser-Meyer-Olkin metric for sampling is enough to 0.734; sphericity test of Bartlett approximation chi square 571.743, df 15, Sig. 0.000 . The results show that the KMO value is 0.734 , which is between $0.7-0.8$, and is suitable for factor analysis. The rotational component matrix is shown in Table 2:

Table 2. Rotational components matrix of consumer attitudes and behavior scale

\begin{tabular}{lcc} 
& & Component \\
& 1 & 2 \\
\hline E11 Product matching & .838 & .114 \\
E21 Public recognition & .807 & .183 \\
E12 Indoor environment & .731 & .145 \\
F12 Reasonable price & .213 & .847 \\
F21 Regular re purchase & .052 & .810 \\
F11 Shop scene & .198 & .728 \\
Extraction method: principal component. & & \\
Rotation method: an orthogonal rotation method with Kaiser standardization. & \\
a. Rotation after 3 iterations of convergence. & & \\
\hline
\end{tabular}

From the Table 2 can be drawn, after factor analysis, the cumulative variance percentage is higher than $65 \%$, the statistical analysis results show that the scale of the construct validity is extremely good. 


\subsection{Influence Model Building}

\subsubsection{Initial Model Validation}

To verify the reliability and validity of the measurement model and the model fitting degree, before the model fit estimates, for "violation of estimate" (Offending Estirnates) check, path coefficient of the effectiveness of the inspection. Through the operation results of AMOS17.0, we get the structure model of this study, as shown in Figure 2:

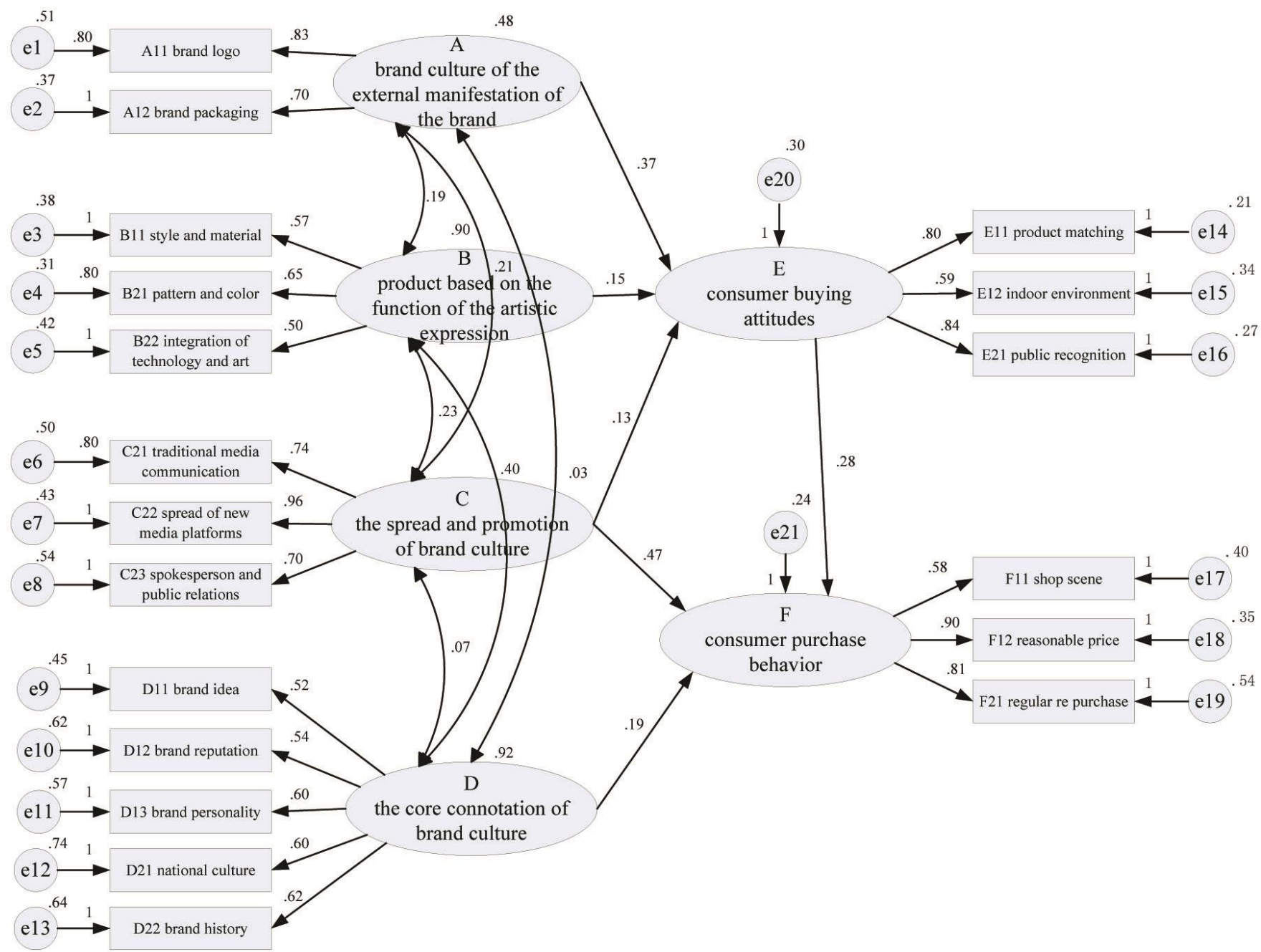

Figure 2. Structure model diagram

The fit index of the structure model is shown in Table 3:

Table 3. Initial fitting index of structure model

\begin{tabular}{cccccccccc}
\hline Model & CMIN & DF & CMIN/DF & GFI & NFI & CFI & TLI & IFI & RMSEA \\
\hline Defaut Model & 217.752 & 140 & 1.555 & 0.944 & .864 & .946 & .934 & .947 & 0.039
\end{tabular}

According to international practice, this paper selects CMIN / DF (chi square free ratio), GFI (goodness of fit index), CFI (comparative fit index), NFI (normed fit index), TLI, RMSEA (approximation error root mean square) six fit index evaluation model. The results show that CMIN/DF is 1.555, less than 2, that can be accepted; RMSEA value is $0.039<0.08$, it can be accepted. GFI, CFI, TLI, IFI are all greater than 0.9, NFI $<0.9$. Comprehensive consideration of the fitting index, overall adaptation good of model, the individual indicators need to be revised.

According to the regression coefficient between the latent variables in the structure model chart 4-1, the hypothesis of the structural model can be studied as shown in Table 4: 
Table 4. Research hypotheses result of structural model figure

\begin{tabular}{lc}
\multicolumn{1}{c}{ Relationship hypothesis of structural model } & Whether to accept \\
H1: The external performance of the brand culture has a significant positive & Yes \\
correlation with the purchase attitude of consumers. & Yes \\
H2: Products based on the functionality of artistic expression has a significant & No \\
positive correlation with the purchase attitude of consumers. & Yes \\
H3: Dissemination and promotion of brand culture has a significant positive & No \\
correlation with the purchase attitude of consumers. & Yes \\
correlation with the purchase behavior of consumers. & H5: Core connotation of brand culture has a significant positive correlation with \\
the purchase attitude of consumers. & Yes \\
H6: Core connotation of brand culture has a significant positive correlation with & \\
the purchase behavior of consumers. & \\
H7: Purchase attitude of brand culture has a significant positive correlation with \\
the purchase behavior of consumers.
\end{tabular}

\subsubsection{Model Modification Analysis}

When the researchers put forward a hypothesis model according to theory of literature or rule of thumb, examined the adapter can't fit with the observing data, said model must be modified. This study should first remove the 2 path effect of brand culture communication on consumers attitude and brand culture connotation influence on consumers attitude, in the Amos run again the following results as shown in Figure 3:

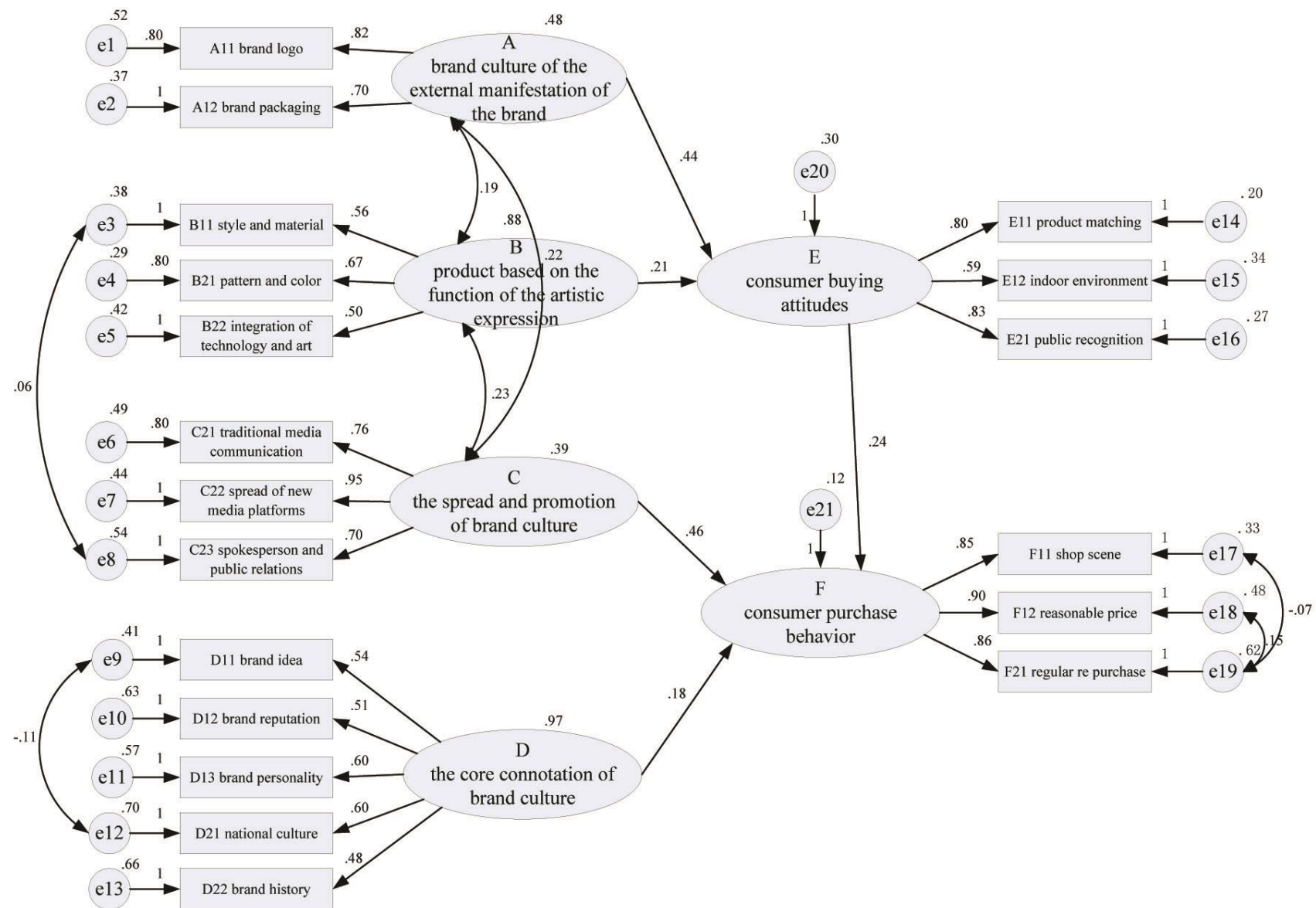

Figure 3. Structure model diagram of modification 
The model fitting index corrected chi square value decreases, the indicators has improved, see Table 5:

Table 5. correction model fitting index

\begin{tabular}{cccccccccc}
\hline Model & CMIN & DF & CMIN/DF & GFI & NFI & CFI & TLI & IFI & RMSEA \\
\hline Defaut Model & 187.055 & 141 & 1.327 & .951 & .883 & .968 & .961 & .968 & 0.03
\end{tabular}

The comprehensive analysis of the above results, the correction model as the final model results, the structure model of the variables in the regression equation is:

a. Direct Impact------ home textile consumer buying behavior $=0.54$ (cultural dissemination and promotion) +0.32 (cultural core connotation) +0.31 (home textile consumers purchase attitude)

b. Indirect Impact ------ home textile consumer buying behavior $=0.31 * 0.45$ (brand external performance) $=0.140$ (brand external performance); home textile consumer buying behavior $=0.31 * 0.29$ (home textile functional artistry) $=0.09$ (home textile functional artistry)

c. Total Impact ----- home textile consumer buying behavior $=0.54$ (cultural dissemination and promotion) +0.32 (cultural core connotation) +0.31 (home textile consumers purchase attitude) +0.14 (brand external performance) + 0.09 (home textile functional artistry)

According to the regression equation, the influence of five factors on the consumer purchase behavior from large to small is as follows: cultural dissemination and promotion, cultural core connotation, home textile consumers purchase attitude, brand external performance, product functional artistry, the standardized regression coefficients are: $0.54,0.32,0.31,0.14,0.09$, and achieves significant impact on the level.

\section{Conclusion and Prospect}

This study is based on theory of brand culture constitute and brand culture effect on consumers, combined with home textile culture and consumer characteristics, study the influence factors of the brand culture by consumers purchase behavior in home textiles. At the same time, combined with home textile art, science and technology and the development trend of personalized, brand external performance, product artistic performance, advertising communication behavior, core connotation elements of brand culture on the home textile consumer behavior are fully discussed and quantified. The influence of five connotation factors of brand culture on the consumer purchase behavior from large to small is as follows: brand cultural dissemination and promotion, brand cultural core connotation, home textile consumers purchase attitude, brand cultural external performance, home textile product functional artistry.

Based on the research results about influence model of brand culture on home textile consumption behavior, the enterprise with its own advantages and disadvantages and actual demand, to build enterprise brand culture promotion scheme, put forward the suggestion that have influence on consumer behavior, strategies, and make the enterprise characteristic home textile culture implementation plan, in order to further improve their competitiveness to lay a solid foundation.

The factor screening attention on the brand culture and consumer behavior between the perceivable factors, for the social environment and culture of different countries together to influence, and brand culture marketing input and output value of related issues can be further research. Based on the constructed influence model, according to different brand cultural characteristics, subdivision values characteristics of consumer groups, to study the consumer behavior; and can be further studied about fund input of brand culture construction and consumer behavior to produce the value of the profits of economy. This will be based on a reliable theoretical and practical data for marketing analysis, but also has the feasibility.

\section{Acknowledgement}

This study was funded by innovation project of Shanghai University of Engineering Science, The project name is: Innovation Research on O2O Profit Model of Clothing Retailing.

\section{References}

Annie Tubadji, Brian J.Osoba \& Peter Nijkamp. (2014). Culture-based development in the USA: culture as a factor for economic welfare and social well-being at a county level. Journal of cultural economics, (9).

Chen Jing. (2008). Western consumer behavior influence factor model of deconstruction and perspective. Journal of commercial era, (2), 23-24. 
Daniel G.Muntinga, Edith Smit \& Marjolein Moorman. (2012). Social Media DNA: How Brand Characteristics Shape COBRAs. Journal of advances in advertising research, (3), 121-135. http://dx.doi.org/10.1007/978-3-8349-4291-3_10

Gao Yuan, Li Yang, Meng Xianzhong \& Xie Peihong. (2011). Brand experience how to influence brand loyalty -----Also on the mediation effect of product involvement. Journal of soft science, (7), 126-130.

Hu Mo \& Xia Jianming. (2011). Research on brand culture constitute elements and the propagation path. Journal of modern management science, (2), 17-19.

Huang Ming \& Xue Yunjian. (2012). Brand culture strategy innovation based on brand value promotion (Three) ------ Research on the construction of brand culture strategy. Journal of culture enterprise research, (6), 58-60.

Wu Zhaochun. (2011). Review of the research on "culture" in marketing. Journal of commercial era, (9), 34-35.

Yu Xiaolin \& Chen Jianwei. (2013). Study on the ways of creating clothing brand culture based on consumer evaluation. Journal of shandong textile science \& technology, (4), 41-44.

Zhang Liming. (2011). Empirical Study on the key factors of cultural integration of Chinese enterprises transnational merger and acquisition. Xiamen University. 